\title{
PATTERNS OF FAMILY FUNCTIONING AS PREDICTORS OF PARENTING STYLE AMONG THE LEFT-BEHIND FAMILIES OF GULF MIGRANTS
}

\author{
Shameer V. ${ }^{1}$, Joseph I. Injodey ${ }^{2}$ \\ ${ }^{1}$ PhD Research Scholar, Department of Social Work, Rajagiri College of Social Sciences, Kochi, \\ Kerala, India. \\ ${ }^{2}$ Research Guide, Department of Social Work, Rajagiri College of Social Sciences, Kochi, Kerala, \\ India.
}

Article DOI: https://doi.org/10.36713/epra7484

DOI No: 10.36713/epra7484

Correspondence Author: Shameer V.Rajagiri College of Social Sciences, Kochi, Kerala, India.

\begin{abstract}
Understanding the family functioning of left-behind families of gulf migrants and how they relate to parenting style is critically important to social workers worldwide. The study examined the associations between family functioning patterns and mothers' parenting styles among the left-behind families of gulf migrants. The circumplex model of family functioning put forwarded by David $\mathrm{H}$. Olson served as the study's theoretical framework. Family Adaptation and Cohesion Evaluation Scale (FACES IV) (Olson, FACES IV and the Circumplex Model: Validation Study, 2011) was used for testing family functioning, and the Parenting Style and Dimension Questionnaire (Robinson, Mandleco, Olson, \& Hart, 2001) was used for testing the parenting style and its dimensions. The study's main findings suggest that balanced cohesion and flexibility correlate with the authoritative parenting style. It also revealed that the authoritarian parenting style correlates negatively with all the functional family functioning patterns: balanced cohesion and flexibility. Authoritarian parenting style correlates positively with all the dysfunctional patterns of family functioning also. While, permissive parenting style correlates positively only with balanced cohesion, disengaged, enmeshed, family communication, and family satisfaction dimension of family functioning. This benchmark study offers family social work practitioners information to assist families and contribute to family social policies.
\end{abstract}

KEYWORDS: family functioning, parenting style, left-behind families.

\section{INTRODUCTION}

The increasing emphasis on family as a unit has evolved in family social work and developments in family sociology. Knowledge of current research on the correlation between family functioning and parenting style in the left-behind families of gulf migrants is essential to provide optimum service. It is the first step toward sound practice in an era of evidence-based social work.

International migration is used as a livelihood strategy by many people all over the world. The migrants bring economic benefits to their left-behind family members but incur severe social strains. One of the significant pressures is on leftbehind wives in parenting their children in the husband's absence. Discourse on this theme in labour migration is yet to gain momentum in India. In men's absence, wives have to carry the sole responsibility for children. The literature on children left behind in the Indian context remains sparse. The spotlight is placed on wives' perceived family functioning and how different family functioning patterns are reflected in parenting style. The literature gave a rich background for this work and conceptualised the relationship between family functioning and parenting style.

Children are left behind if one or both parents migrate out for work (Connelly \& MaurerFazio, 2016). With the number of men migrating as labourers, their left-behind children require more 
attention from their mothers. There have been contradictory impacts of migration on the education of left-behind children. Research has shown positive effects like the rise in school enrolment, more investment in children's education, and improved school performance. On the other hand, negative consequences were also found. There are situations where remittance flows cannot compensate for the absence of a parent. These children seem to have a risky lifestyle. They suffer from high levels of stress, sadness, emotional disruption, loneliness and abandonment.

In some cases, these children are left with relatives that may hamper their care and well-being. Studies have suggested that left-behind children and adolescents are more likely to experience drug abuse, teenage pregnancy, psychosocial problems, as well as violent behaviours (Garza, 2010).

Separation of family over a long time takes a toll on the marital and parental relationships and threatens the family's stability as a unit. When husbands emigrate from a nuclear family setup, then the gender roles of left-behind wives undergo noticeable changes. They undertake complete responsibility for managing remittance, participating in social gatherings, handling bank transactions, visiting government offices, and others, along with their traditional gendered roles like home management and child care. In the absence of their husbands, wives act as single parent and earn the love and respect of their children.

Oh (2014) stressed the migrant families' subjective well-being is placed on two mutually conflicting elements. The first element is the financial benefits achieved by migration. The second element is psychological grief among the family members because of the separation of the family due to migration. Hence, the remittance flow is a central point that tries to balance the problematic outcomes of migration. The levels of happiness are determined only when remittances substantially support household income. Accordingly, when household income is modest to the transmitted remittance, the happiness level of remittances receiving and nonremittance receiving households is the same. But, less happiness prevails among the families with modest remittances in comparison to larger remittance flow households.

Similarly, Kerala's study also showed remittances played a significant role in enhancing the family member's educational status (Zachariah \& Rajan, 2012). Money received through remittances is used to meet expenses related to education and provide healthcare; thus, remittances act as a development mechanism (Mahapatro, Bailey, James, $\&$ Hutter, 2017). There is a radical change in family member's circumstances due to remittances. One of the primary uses of remittances is to purchase food items for the family. Remittances are also a crucial monetary source to reduce poverty among migrant households. They are used for different purposes, such as meeting basic needs, investing and paying debts and loans, and purchasing better food. The available research on remittance utilisation supports the point that it allows the households to meet their basic needs- food, shelter and clothing. Hence, remittances are a vital source of a household's consumptions income (Sikder \& Ballis, 2013).

As Theodore Dix pointed out, psychological well-being has been suggested to be one of the most critical determinants of parenting (Dix, 1991). For example, according to Belsky (1984), only a mature adult who enjoys an adequate degree of well-being can adopt a nurturing orientation in parenting and provide growth-promoting care. In addition, it has been suggested that parental well-being also plays a role in the associations between a child's temperament and parents' parenting styles.

\section{THEORETICAL FRAMEWORK}

The Circumplex Model of Family functioning was initially developed by David Olson, Douglas Sprenkle, and Candyce Russell to bridge the gap between theory, research, and practice in family therapy (Olson, 1989). The Circumplex Model of family functioning focuses on the three central dimensions of the marital and family system: cohesion, flexibility and communication. Cohesion is explained as the emotional bonding that family members have toward one another (Olson, 2019). Family flexibility is described as the quality and expression of leadership and organisation, role relationship, and related rules and negotiations. As previously used in the model, flexibility was described as a change in family leadership, role relationships, and associated practices. Finally, communication is defined as the positive communication skills used by family members. The communication dimension is considered a facilitating dimension that helps families alter their cohesion and flexibility (Olson, 2011).

There are three significant hypotheses derived from the Circumplex Model. First, balanced couples and families tend to be more functional (happy and prosperous) than unbalanced systems. Second, balanced families have more positive communication than unbalanced families. Third, balanced families will effectively modify cohesion and flexibility to deal with stress and development change, as compared to unbalanced systems (Olson, 2019)

\section{Family functioning and parenting style}

The Family system theory assumes that there is a significant correlation between family 
dynamics and parenting style. According to Olson's hypothesis (2011), certain parenting styles rely on the patterns of family functioning. This is operationalised in FACES IV. Olson and Gorall believe that Diane Baumrind's theory about parenting styles corresponds with their family functioning theoretical model. Relying on Shaffer's model, D. Baumrind (1968) defined three fundamental parent-child relationships: authoritarian, authoritative and permissive. According to the systemic perspective, the authoritative style can easily be traced from balanced family systems. A balanced family system is a unit of family where there is adequate cohesion and flexibility.

The authoritarian style could be seen in enmeshed families, and the absence of flexibility is visible in families with unbalanced rigid functioning. The rules in such families are usually very stringent, and disobeying them usually has consequences. In contrast, a permissive parenting style should be present in families with a high level of cohesion and chaos. This will result in togetherness, but the roles and rules are either unclear or continuously change.

\section{METHOD}

Design

A quantitative approach was used to account for the experiences of left-behind families of the Gulf migrants. Two standardised tools, Family Adaptation and Cohesion Evaluation Scale-IV (FACES IV) by Olson (2011) and Parenting Style and Dimension Questionnaire (PSDQ) by Robinson et al. (2001), were used to collect the quantitative data. The present study was conducted in the Malappuram district of Kerala in India, among 384 left-behind women identified as the wives of Gulf migrants and continue to live in their native land with the remaining family members. A purposive sampling method was adopted to select the sample from the population through the ward members of different Gramapanchayts in the Malappuram district, where there was a high prevalence of Gulf migration.

\section{Instruments}

FACES IV (Family Adaptation and Cohesion Scales) (Olson, 2011) was used to measure family functioning. According to the instrument, balanced cohesion and balanced flexibility are the functional dimensions. The dimensions such as disengaged, enmeshed, chaotic and rigid, are considered unbalanced family relations. The instrument is also measuring the dimensions of communication in the family and satisfaction with the family. Parenting Styles \& Dimensions Questionnaire (2001) was used to assess the parenting styles and their dimensions. It considers the authoritative, authoritarian and permissive parenting styles based on Diana Baumrind's parenting styles model. The questions were reviewed to ensure that the content and language were appropriate for the population under study.

\section{RESULTS AND INTERPRETATIONS}

The participants' socio-demographic characteristics comprised the age, education, employment and monthly income are presented below.

Table 1.

Descriptive characteristics of the participants

\begin{tabular}{lll}
\hline Variable & Frequency & Percent \\
\hline Age & & \\
Early adulthood & 332 & 86.5 \\
Early middle age & 48 & 12.5 \\
Advanced middle age & 4 & 1
\end{tabular}

Education

Secondary

Higher Secondary

Graduation

Post-Graduation

Others 
Employment

$\begin{array}{lcc}\text { Employed } & 125 & 32.6 \\ \text { Unemployed } & 259 & 67.4\end{array}$

Monthly Income

Below 25000

$25001-50000$

$50001-75000$

The mean age of the respondent was $33.27 \pm 6.75$ years in the current population. The age of the respondents ranged from 20 to 54, and thus, age was categorised as early adulthood (18-40), early middle age (40-50) and advanced middle age (50-60). Education is measured based on years of formal education completed by the respondents. The table shows that most respondents $(n=165,43 \%)$ have completed their secondary education. It could also be seen that a considerable proportion of the respondents have completed their higher secondary education $(\mathrm{n}=98, \quad 25.5 \%) \quad$ and graduation $(n=82,21.4 \%)$. Only a small proportion of the respondents have attained a Post Graduate degree $(7.8 \%, \mathrm{n}=30)$ and education in other streams $(n=30,2.3 \%)$.

The table also depicts that majority of the respondents were unemployed, representing 68 per cent $(n=259)$ of the total population. Only 32 per cent $(n=59)$ of the respondents were employed. The monthly income of the majority of the population $(\mathrm{n}=228,59.4 \%)$ ranged between 25001-50000 Rupees. Twenty per cent $(n=78)$ of the respondents belong to the category of 50001-75000 Rupees, and 13 per cent $(n=52)$ of the population belong to the category below 25000 Rupees. Only a few per cent of them had monthly income ranging between 75000 100000 Rupees $(\mathrm{n}=26 ; 7 \%)$.

Table 2.

Descriptive statistics of the dimensions of family functioning

\begin{tabular}{lll}
\hline Variable & Mean & Standard Deviation \\
\hline Balanced Cohesion & 67.9141 & 15.49869 \\
Unbalanced Disengaged & 49.5573 & 16.09719 \\
Unbalanced Enmeshed & 57.1458 & 19.38748 \\
Balanced Flexibility & 70.1979 & 14.43424 \\
Unbalanced Rigid & 53.3151 & 21.10924 \\
Unbalanced Chaotic & 34.6146 & 20.11254 \\
Family Communication & 68.4557 & 30.30563 \\
Family Satisfaction & 3.8516 & 1.39800 \\
& &
\end{tabular}

As the next step, descriptive statistics for the dimensions of family functioning were analysed and presented in Table 2. The given data could be understood that the functional dimensions such as balanced cohesion and balanced flexibility are relatively elevated. The ratio score between the balanced and unbalanced scales is above one. (Cohesion ratio is 1.5 , flexibility ratio is 1.4 , and the total Circumplex ratio is 1.4) which shows that the families in the examined sample are functional and balanced. To be more precise, balanced cohesion and balanced flexibility are the dominant patterns of family functioning in the given population. 
Table 3.

Descriptive statistics of the dimensions of parenting styles

\begin{tabular}{lll}
\hline Variable & Mean & Standard Deviation \\
\hline Authoritative Parenting & 3.9851 & .53473 \\
Authoritarian Parenting & 2.8012 & .54118 \\
Permissive Parenting & 14.6693 & 3.24097 \\
\hline
\end{tabular}

Descriptive analysis of the parenting styles showed that the mean and standard deviation of the different dimensions were: Authoritative parenting

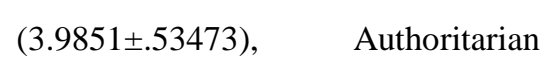

(3.9851 \pm .53473$), \quad$ Authoritarian parenting

(14.6693 \pm 3.24097$)$. parenting

\section{Prediction of the authoritative parenting style based on the dimensions of family functioning}

Table 4

Results of Multiple Linear Regression Analysis: Prediction of Authoritative Parenting Style based on Dimensions of Family Functioning

\begin{tabular}{llllll}
\hline Model & $\mathbf{R}$ & $\mathbf{R}^{\mathbf{2}}$ & Adjusted $\mathbf{R}^{\mathbf{2}}$ & $\mathbf{F}$ & $\boldsymbol{\rho}$ \\
\hline $\mathbf{1}$ & .46 & .21 & .197 & 12.76 & .000 \\
\hline
\end{tabular}

Multiple linear regression was used to explain authoritative parenting style based on the family functioning dimensions-balanced cohesion, disengaged, enmeshed, balanced flexibility, rigid, chaotic, family communication, and family satisfaction. The overall model explains a $21.4 \%$ variation of authoritative parenting, and it is significantly helpful in explaining authoritative parenting style $F(8,375)=12.76, p<.001$. The model demonstrates that with a one-unit increase in balanced cohesion, the authoritative parenting style increases by .007 , which was a significant change, $t$ $(375)=3.099, p<.05$. With one unit increase in disengaged dimension, the authoritative parenting decreases by .003, which was a significant change, $t$ (375) $=-1.970, p=<.05$. With one unit increase in enmeshed dimension, authoritative parenting style decreases by .001 , which was not a significant change, $t(375)=.368, p>.05$. With a one-unit increase in balanced flexibility dimension, authoritative parenting style increases by .013, which was a significant change, $t(375)=4.428, p<.001$. With one unit increase in rigid dimension, authoritative parenting style decreases by .007 , which was a significant change, $t(375)=-4.388, p=<.001$. With one unit increase in chaotic dimension, authoritative parenting style decreases by .001 , which was not a significant change, $t(375)=-.434, p=$ $>$.05. With one unit increase in the family communication dimension, the authoritative parenting style increases by .05 , which was not a significant change, $t(375)=.42, p>.05$. With a oneunit increase in family satisfaction dimension, the authoritative parenting style increases by 1.19 , which was a significant change, $t(375)=9.66, p<.001$.

The final predictive model was:

Authoritative parenting style $=2.831$ $+(.75 *$ Balanced cohesion $)+(.08 *$ Disengaged $)+\left(.15^{*}\right.$ Enmeshed $)+(.-93 *$ Balanced flexibility $)+(-$ $.26 *$ Rigid $)+(-.05 *$ Chaotic $)+\quad(.05 *$ Family communication $)+(1.19 *$ Family satisfaction $)$.

The present study found that functional family patterns positively correlated with authoritarian parenting style, and all the dysfunctional family patterns negatively associated with authoritative parenting styles. The overall model accounted for a $21.4 \%$ variation in authoritative parenting style. Individually, through subdimensions, it shows a strong positive correlation with balanced cohesion and balanced flexibility. On the other hand, it also exhibits a strong negative relationship with the unbalanced dimensions such as disengaged enmeshed, rigid and chaotic. There is also a significant positive correlation between family communication and satisfaction with authoritative parenting style.

Prediction of the authoritarian parenting style based on the dimensions of family functioning Table 5

Results of Multiple Linear Regression Analysis: Prediction of Authoritarian Parenting Style based on Dimensions of Family Functioning

\begin{tabular}{llllll}
\hline Model & $\mathbf{R}$ & $\mathbf{R}^{\mathbf{2}}$ & Adjusted $\mathbf{R}^{\mathbf{2}}$ & $\mathbf{F}$ & $\boldsymbol{\rho}$ \\
\hline $\mathbf{1}$ & .33 & .11 & .093 & 5.884 & .000 \\
\hline
\end{tabular}

Multiple linear regression was fitted to explain authoritarian parenting style based on the dimensions of family functioning such as balanced cohesion, disengaged, enmeshed, balanced flexibility, 
rigid, chaotic, family communication and family satisfaction. The overall model explains $11.2 \%$ variation of authoritarian parenting, and it is significantly helpful in explaining authoritarian parenting style, $F(8,375)=5.884, p<.001$. The model demonstrates that with a one-unit increase in balanced cohesion, the authoritarian parenting style decreases by .005 , which was found to be a significant change, $t(375)=-2.204, p<.05$. With one unit increase in disengaged dimension, the authoritarian parenting increases by .002 , which was not a significant change, $t(375)=-.880, p=>.05$. With one unit increase in enmeshed dimension, authoritarian parenting style increases by .003 , which was not a significant change, $t(375)=1.462, p=$ $>.05$. With a one-unit increase in balanced flexibility, authoritarian parenting style decreases by .011 , which was found to be a significant change, $t(375)=-3.304$, $p<.001$. With one unit increase in rigid dimension, authoritarian parenting style increases by .008 , which was a significant change, $t(375)=4.785, p=<.001$. With one unit increase in unbalanced chaotic, authoritative parenting style increases by .004 , which was found to be a significant change, $t(375)=-.434$, $p=<.05$. With a one-unit increase in family communication, the authoritarian parenting style decreases by .002 , which was not a significant change, $t(375)=-3.71, p>.05$. With one unit increase in family satisfaction, the authoritarian parenting style increases by .073 , which was not a significant change, $t(375)=.783, p=>.05$.

The final predictive model was:

Authoritarian parenting style = $2.830+(.005 *$ Balanced cohesion $)+(.880 *$ Unbalanced disengaged $)+\left(.003^{*}\right.$ Unbalanced Enmeshed $)+(.-$ $011 *$ Balanced flexibility $)+(.008 *$ Unbalanced rigid $)+(.004 *$ Unbalanced chaotic $)+(-.002 *$ Family communication $)+(.073 *$ Family satisfaction $)$.

As shown in Table 4, functional patterns of family relations are connected negatively to the authoritarian dimension of parenting style. In line with the previous studies, all the dysfunctional patterns of family functioning positively correlated with the authoritarian style of parenting. The overall model explains $11.2 \%$ significant variation in authoritarian parenting style.

\section{Prediction of the permissive parenting style based on the dimensions of family functioning \\ Table 6}

Results of Multiple Linear Regression Analysis: Prediction of Permissive Parenting Style based on Dimensions of Family Functioning

\begin{tabular}{llllll}
\hline Model & $\mathbf{R}$ & $\mathbf{R}^{\mathbf{2}}$ & Adjusted $\mathbf{R}^{\mathbf{2}}$ & $\mathbf{F}$ & $\boldsymbol{\rho}$ \\
\hline $\mathbf{1}$ & .33 & .109 & .090 & 5.748 & .000 \\
\hline
\end{tabular}

Multiple linear regression was fitted to explain permissive parenting style based on the dimensions of family functioning such as balanced cohesion, disengaged, enmeshed, balanced flexibility, rigid, chaotic, family communication and family satisfaction. The overall model explains $10.9 \%$ variation of permissive parenting, and it is significantly useful in explaining permissive parenting style, $F(8,375)=5.748, p<.001$. The model explains that with a one-unit increase in balanced cohesion, the permissive parenting style increases by .076 , which was a significant change, $t$ $(375)=5.435, p<.001$. With one unit increase in disengaged dimension, the permissive parenting increases by .023 , which was a significant change, $t$ (375) $=2.235, p=<.05$. With one unit increase in enmeshed dimension, permissive parenting style increases by .014 , which was not a significant change, $t(375)=1.143, p=>.05$. With a one-unit increase in balanced flexibility, permissive parenting style decreases by .095 , which was found to be a significant change, $t(375)=-5.092, p<.001$. With one unit increase in rigid dimension, permissive parenting style decreases by .019 , which was found to be a significant change, $t(375)=-1.913, p=<.05$. With one unit increase in chaotic dimension, permissive parenting style decreases by .004 , which was not a significant change, $t(375)=--.455, p=$ $>05$. With a one-unit increase in family communication dimension, the permissive parenting style increases by .003 , which was not found to be a significant change, $t(375)=-.131, p>.05$. With one unit increase in family satisfaction dimension, the permissive parenting style increases by .237 , which was not a significant change, $t(375)=.428, p=>.05$. The final predictive model was:

Permissive parenting style $=14.216+(.076 *$ Balanced cohesion $)+(.023 *$ Unbalanced disengaged $)+(.014 *$ Unbalanced Enmeshed $)+(-$. $095 *$ Balanced flexibility $)+(-.019 *$ Unbalanced

rigid $)+(. .004 *$ Unbalanced chaotic $)+(.003 *$ Family communication

)$+(.237 *$ Family satisfaction $)$.

This model explains $10.9 \%$ variation in permissive parenting. The dimensions such as balanced cohesion, unbalanced disengaged, unbalanced enmeshed, family communication and family satisfaction were positively correlated with permissive parenting style. At the same time, it is also noted that the balanced flexibility dimension, rigidity, and chaos were negatively associated with the permissive parenting style. 


\section{CONCLUSION}

Family functioning seems to be one of the critical variables contributing to determining parenting style in most populations. The patterns of family functioning are associated with the dimensions of parenting style. This study focused on investigating how the eight dimensions of family functioning predict parenting style among the wives of gulf migrants, as the character of this relationship has received surprisingly little attention.

The results revealed that balanced cohesion and balanced flexibility are the assertive patterns in family functioning. It could also be observed that the balanced dimensions of family functioning are significantly correlated with authoritative parenting style. Furthermore, there is a significant correlation between family communication and satisfaction dimensions with authoritative parenting styles.

In the next step of the analysis, the study revealed that functional patterns of family relations are connected negatively. The dysfunctional patterns are associated positively with the second dimension of parenting style. While analysing the permissive parenting style, it could be observed that the dimensions of family functioning such as balanced cohesion, disengaged, enmeshed, family communication, and family satisfaction were positively correlated. Despite this, it is also noted that the balanced flexibility dimension, rigidity, and chaos were negatively associated with the permissive parenting style. The discussion of the obtained results will line with the systemic approach of marital and family functioning. The results indicate that focusing on strengthening parenting skills should be replaced by influencing the patterns of family functioning for the effects of the intervention on the parental subsystem to be adequate and efficient.

\section{REFERENCES}

1. Alder, E. S. (2010). Age, Education Level and length of Courtship in Relation to Marital Satisfaction. . School of Professional Psychology,, 145. Retrieved from http://commons.pacificu.edu/spp/145

2. Baltes, P., Lindenberger, U., \& Staudinger, $U$. (2006). Life Span Theory in Developmental Psychology (6 ed.). Wiley. doi:10.1002/9780470147658.chpsy0111

3. Baumrind, D. (1968). Authoritarian vs. authoritative parental control. Adolescence, 3(11), 255-272.

4. Belsky, J. (1984). The determinants of parenting: A process model. Child Development, 55(1), 83-96. doi:https://doi.org/10.2307/1129836

5. Connelly, R., \& Maurer-Fazio, M. (2016). Left behind, at-risk, and vulnerable elders in rural
China. China Economic Review, 37, 140-153. doi:https://doi.org/10.1016/j.chieco.2015.10.005

6. Dix, T. (1991). The affective organisation of parenting: Adaptive and maladaptive processess. Psychological Bulletin, 3-25. doi:DOI: 10.1037/0033-2909.110.1.3

7. Garza, R. d. (2010, May). Migration, development and children left behind: a multidimensional perspective. Social and Economic Policy, 1-37.

8. Goelman, H., Zdaniuk, B., Boyce, W. T., Armstrong, J., \& Essex, M. J. (2014, August). Maternal mental health, child care quality, and children's behavior. Journal of Applied Developmental Psychology, 35(4), 347-356. doi:DOI: 10.1016/j.appdev.2014.05.003

9. Gorney, S., \& Cox, C. (1973). How women can achieve fullfillment after forty. New York: Dial Press.

10. Hurlock, B. E. (2006). Developmental Psychology: A Life Span Approch (5 ed.). New Delhi: Tata McGraw Publishing Cmpany Limited.

11. International Organization for Migration. (2019). International Migration Law: Glossary on Migration. Geneva: International Organization for Migration.

12. Mahapatro, S., Bailey, A., James, K., \& Hutter, I. (2017). Remittances and household expenditure patterns in India and selected states, Migration and Development. Migration and Development, 6(1), 81-103. doi:10.1080/21632324.2015.1044316

13. Oh, Y. A. (2014, September). Life Satisfaction of the Families of Migrants in the Philippines. Asian and Pacific migration journal, 23(3), 249-271. doi:DOI: 10.1177/011719681402300301

14. Olson, D. H. (1989). Circumplex model of family systems VIII: Family assessment and intervention. In D. H. Olson, C. S. Russell,, \& D. H. Sprenkle, Circumplex model: Systemic assessment and treatment of families (pp. 7-50). New York: Routledge.

15. Olson, D. H. (2011, January). FACES IV and the Circumplex Model: Validation Study. Journal of Marital and Family Therapy, 37(1), 64-80. doi:doi: 10.1111/j.1752-0606.2009.00175.x

16. Olson, D. H. (2019, June). Circumplex Model of Marital and Family Systems: An update. Journal of Family Theory \& Review, 11, 199-211. doi:DOI:10.1111/jftr.12331

17. Rahman, M. M. (2015). Migrant Indebtedness: Bangladeshis in the GCC Countries. International Maigration, 53(6), 205-219. doi: https://doi.org/10.1111/imig.12084

18. Robinson, C. C., Mandleco, B., Olson, S. F., \& Hart, C. (2001). The parenting styles and dimensions questionnaire (PSDQ) (Vol. 3). Sage Publications.

19. Rollins, B. C., \& Feldman, H. (2010). Marital satisfaction over the family life cycle. Journal of Marriage and the Family(32), 20-28. 
20. Sikder, M., \& Ballis, P. H. (2013). Remittances and life chances: a study of migrant households in rural Bangladesh. Migration and Development, 2(2), 261-285. doi:10.1080/21632324.2013.814322

21. Zachariah, K. C., \& Rajan, S. I. (2012, September 1). Inflexion in Kerala's Gulf connection: report on Kerala migration survey 2011. 